\title{
Why deontologists should reject agent-relative value and embrace agent-relative accountability
}

\author{
Rudolf Schuessler
}

Published online: 28 October 2020

(C) The Author(s) 2020

\begin{abstract}
This paper claims that deontological and consequentialist ethics are best distinguished with reference to different assumptions concerning moral accountability and accounting. Deontological ethics can thereby be defended against the accusation of inordinate concern with the moral purity of agents. Moreover, deontological ethics can and should reject being based on the concept of agent-relative value. Even under the assumption that deontological ethics can be consequentialized, agent-relative value need not play a fundamental role. This is not the same as denying agent-relativity a key role in deontological ethics. Deontological moral accounting of universal value should be regarded as agent-relative, whereas consequentialist accounting assumes a shared moral account of all moral agents.
\end{abstract}

Keywords Deontology · Consequentialization · Agent-relativity · Agent-relative value $\cdot$ Accountability

In recent decades, it has become commonplace to characterize deontological ethical theories as agent-relative (or agent-centered). ${ }^{1}$ But from whence does the agentrelativity of deontology $y^{2}$ or its moral reasons arise? The present paper claims that

\footnotetext{
1 See Ridge (2017). On the difficult business of delineating what makes ethics deontological, see Alexander and Moore (2016), Gaus (2001), McNaughton and Rawling (2007).

For helpful comments and suggestions, I am grateful to Vuko Andrić, Jonas Franzen, and the participants of the conference "Spheres of Morality" (Bremen, August 2018). Many thanks also to two anonymous referees who pressed me on important questions.

2 In the following used synonymously with deontological ethics.
}

R. Schuessler $(\bowtie)$

Institute of Philosophy, University of Bayreuth, 95440 Bayreuth, Germany

E-Mail: rudolf.schuessler@uni-bayreuth.de 
deontological ethics are best characterized by the assumption of agent-relative moral accountability, and specifically a restricted form of accountability which, in contrast to consequentialist accountability, respects the separateness of persons. This claim has important implications for how agent-relativity is best understood to distinguish deontology and consequentialism, and for the justification of deontological constraints.

Alternatively, deontological agent-relativity might also be based on the concept of agent-relative value. However, it is unnecessary and, as I proceed to show, detrimental to give agent-relative value a fundamental role for the conception of deontology. (It may, of course, play a secondary role because some innocuous values may be agent-relative). It is important in this respect that the concept of agent-relative value figures centrally in attempts to consequentialize deontological theories. ${ }^{3}$ Consequentializing, put shortly, is to formulate an ethical theory as a version of act consequentialism (see below). Some influential moral philosophers claim that every reasonable deontological ethical theory can be consequentialized. ${ }^{4}$ If this is true, and if agentrelative value is necessary for the consequentialization of deontological theories, it cannot simply be shrugged off. One way of coping with this challenge is to deny the relevance of consequentialization..$^{5}$ I will not embark on this route here but take a second one, arguing that even consequentialized deontological theories need not rely on agent-relative value. Agent-relative value thus turns out to be dispensable at the core of deontological ethics, regardless of one's stance towards the project of consequentialization. ${ }^{6}$

Ridding deontology of fundamental agent-relative value also helps to rebut the accusation of undue concern with an agent's own moral purity that is often voiced against deontological ethics. Dependency on agent-relative value appears problematic because 'value for' an agent is the most straightforward form of agent-relative value, and egoistical value is the simplest form of 'value for' an agent. ${ }^{7}$ Deontological ethics therefore risk being accused of fostering an agent's undue concern

\footnotetext{
3 Dreier (2011), Louise (2004), Portmore (2011: 62). Thomas Nagel is a non-consequentialist who assumes the agent-relative value of fundamental rights in Nagel (2002: 36).

4 See Betzler and Schroth (2019), Dreier (2011), Portmore (2011), while Brown (2011) disagrees. Whoever accepts Brown's denial of possible consequentualization may follow the present paper for the sake of the argument. It then shows that if consequentialization were possible, agent-relative value need not be involved, or more generally that strict deontological constraints can be justified without recourse to agentrelative value.

5 See Schroeder (2017). Hurley (2013) rather claims that theories that can be consequentialized can also be deontologized. Hence, consequentialism and deontology remain on a par even if consequentialization is possible.

6 A denial of agent-relative value is also recommended in Korsgaard (1993), but for very different reasons from the present. Korsgaard is mainly concerned with showing that deontological reasoning is not purely agent-relative or subjective. This is less bold than Dougherty's (2013) claim that deontological ethics can be formulated in an agent-neutral way (for a critique, see Hammerton 2017). By contrast, I consider traditional deontological ethics, including Kant's, as agent-relative due to assumptions of accountability, but claim that they need not employ agent-relative values. Hence, I also disagree with Foreman (2014) who regards agentrelative intentions as central to Kantian ethics. A key role of agent-relative intentions would strengthen the objection of inordinate concern with one's purity which is discussed below.
}

7 See Schroeder (2007) and Section 2 below. 
with her own 'moral purity' (an agent-relative and egoistical value) when ruling out the prevention of catastrophes through actions that violate moral constraints. In the face of this objection, deontologists should not ground the justification of deontological constraints on agent-relative value. However, they should also look for other ways of rebutting the purity objection, not least because this objection can at first glance also be raised against attempts to characterize deontology by restrictions of accountability that allow agents to retain pure hands in hard cases of possible value maximization. It is therefore significant that restricted accountability can be plausibly interpreted in ways that do not prioritize an agent's own moral purity. The purity objection can thus successfully be refuted.

Section 1 will briefly introduce the concepts of agent-relativity and agent-relative value in relation to consequentialist and deontological ethics. Section 2 starts with Mark Schroeder's critique of the concept of agent-relative value and then shows how its defenders might respond with an eye on the project of consequentializing deontological ethics (with a focus on James Dreier's response). Section 3 shows that models of agent-relative accountability are better suited to represent the explanatory structure of deontological theories than the assumption of agent-relative value. ${ }^{8}$ Section 4 develops a specific model, the key account model, to document how agent-relative value can be bypassed even in an otherwise value-based exposition of deontological theories and deontological constraints. Section 5 fends off a specific objection against the suggested model of accounting, the claim that it falls prey to a 'paradox of deontology' resulting from tradeoffs of core deontological values for a single person and different times. Section 6 sketches how the key account model might be used in the consequentialization of deontological theories obviating any need for agent-relative value. The concluding Section 7 wraps the paper up.

\section{Agent-relativity and agent-relative value}

Deontological ethics are often assumed to be agent-relative. Specifically, the constraints they impose are thought to depend on agent-relative reasons for moral action. Deontological agents are obligated not to lie themselves, instead of seeing to it that as few people as possible lie. This example gives rise to a simple first idea of agentrelativity. A moral demand $\mathrm{D}^{*}$ seems to be agent-relative iff $\mathrm{D}^{*}$ applies to specific agents but not to all agents. Reasons would then be agent-relative iff they are reasons for specific agents without being reasons for all agents. ${ }^{9}$ As for agent-relative value, personal well-being might be a good example of it. My well-being is a value for me but usually not in the same way for you. If you are a well-being maximizing consequentialist, my well-being will be a part of your concern but not the main target of value maximization. To the extent that a person's well-being guides her egoistical value maximization, it is therefore an agent-relative value. This also shows that we

\footnotetext{
8 Readers who are not interested in the discussion on deontological constraints and agent-relative value or familiar with it may directly jump to Section 3 .

9 Ridge (2017).
} 
should be prepared to associate agent-relativity not only with a restriction of reasons to persons but also with variations in the strength of reasons for different persons.

Unfortunately, it is impossible to construct satisfactory general accounts of agentrelativity along these intuitive lines alone. The current debate on agent-relativity reveals a plethora of complications. One of the more widely accepted characterizations of agent-relativity was formulated by David McNaughton and Piers Rawling, and has been further modified by Matthew Hammerton to ward off objections. Hammerton formulates his definition of agent-relativity for moral rules but indicates that it also holds for moral reasons. I adapt his definition accordingly: ${ }^{10}$

A moral reason for action is agent-relative iff, when the reason is represented with the form ' $(\mathrm{x})(\mathrm{x}$ has reason to act* thus that $[. .]$.$) ', there is an ineliminable$ occurrence of ' $\mathrm{x}$ ' in the square brackets that is bound by the initial universal quantifier.

A moral reason for action is agent-neutral iff it is not agent-relative.

Hence, a moral reason for a person $x$ is linked to an action-guiding demand in whose description the same person $x$ is ineluctably involved. It is presently not necessary to delve deeper into the intricacies of agent-relativity because the understanding of deontological reasoning promoted in this paper quite straightforwardly satisfies not only the McNaughton-Rawling-Hammerton definition of agent-relativity but many others, too. General definitions of agent-relativity need to cater for all possible cases, whereas we will only deal with a clear-cut case. The presently relevant aspects of agent-relative value will be discussed in Section 2.

However, why should we specifically be preoccupied with agent-relative value? In modern ethical theorizing, a peculiar role of agent-relative reasons is often acknowledged for deontological ethics. It does, of course, not follow that the reasons in question must arise from considerations of value. In fact, many deontologists will deny this, and I too will suggest an alternative: grounding deontology on agentrelative moral accountability. Deontological accountability should be regarded as agent-relative in ways that consequentialist accountability is not. Nevertheless, there are reasons to combine this claim with an analysis why deontological ethics should not rely on agent-relative value in the justification of moral constraints. To begin with, it is unsatisfactory to just assume the agent-relativity of deontological reasons. We need to understand what renders deontological reasons agent-relative, and differences in value assumptions between deontological and consequentialist theories are a prominent potential starting point for this task. For this reason, it needs to be

\footnotetext{
10 Hammerton (2019: 247) based on McNaughton and Rawling (1991, 1995): "A rule expressing a moral requirement is agent-relative iff, when the rule is represented with the form ' $(\mathrm{x})(\mathrm{x}$ must $\{$ verb] that $[\ldots])$ ', there is an ineliminable occurrence of ' $\mathrm{x}$ ' in the square brackets that is bound by the initial universal quantifier. A rule expressing a moral requirement is agent-neutral iff it is not agent-relative." The asteriks* indicates that for reasons of greater intuitiveness Hammerton's placeholder ' $\{$ verb $\}$ ' has been replaced in the present definition by the verb 'act thus that' which he uses in some examples. For the change from rules to reasons, see Hammerton (2019: 239): "The key idea behind the agent-relative/agent-neutral distinction is the thought that some moral rules (or reasons, or theories) give agents a special focus on themselves, their actions, or states of affairs concerning them". For the debate on agent-relativity/agent-neutrality, see Ridge (2017), Bykvist (2018).
} 
shown that structures of moral accounting form a better starting point. Moreover, it is important that what deontologists and consequentialists achieve when they are successful can be described as a universally morally best state of the world, although with different conceptions of what makes a moral state of the world optimal. It should therefore be emphasized that as far as they are concerned with value, deontologists and consequentialists are basically concerned with universal value, not agent-relative value.

Let me add a caveat. A strategy of dissociating deontological constraints from agent-relative value does not rule out that deontological ethics might use agentrelative value elsewhere in less harmful ways. In some interpretations, for instance, Kantian ethics may allow for agent-relative value with respect to imperfect duties. That is, agents may in some circumstances be allowed to prioritize the development of their own talents to helping distant others. There is no harm in this assumption because the agent-relative reasons for developing one's talents can be overridden, for instance, by humanitarian reasons to help persons in dire need. ${ }^{11}$ Agent-relativity seems most problematic if it cannot be overridden. For this reason, we will concentrate on the nexus between agent-relativity and strict deontological constraints.

Finally, as indicated, agent-relative value plays a major role in attempts to consequentialize deontological ethics. Many deontologists reject the idea that deontological theories can or should be brought into a form that turns them into variants of consequentialism. However, consequentialization is a way to explore the common ground between two hostile superpowers of modern ethics, and I am for détente in this respect. For this reason, I will show that my assumptions concerning deontological accountability are compatible with consequentialization, although deontological and consequentialist approaches remain significantly different even after consequentialization.

\section{Schroeder's critique and Dreier's response}

Mark Schroeder's criticism of agent-relative value and its links to consequentialization are good starting points for our further discussion. Schroeder argues that the concept of agent-relative value, at least to the extent to which it is relevant for deontology or consequentialization, is ill-founded and not intelligible on deeper inspection. ${ }^{12}$ Schroeder shows, for instance, that in the context of deontological constraints, an agent-relative good should not be mistaken as 'good for' an agent. Pleasure may be 'good for' a person in the way in which pleasure is good for those who experience it. Yet compliance with a deontological constraint is not necessarily good in this way for compliant agents. There is no necessary nexus between doing one's duty and preference satisfaction or happiness.

It would also be wrong to assume that the agent-relativity of value (should there be any) resulting from compliance with a strict constraint arises from an agent's

\footnotetext{
11 Kantians may, of course, already consider the outlined interpretation as inappropriate if they think that it misrepresents Kant, but I am not here concerned with the question what Kant really meant.

12 Schroeder (2007).
} 
mere personal valuing or point of view. Such perspectivism would undermine the constraint and open the possibility of different individual views on the validity of a constraint. Deontological ethics typically insist that a constraint, such as the prohibition of lying, is universally binding, regardless of individual ethical perspectives.

In Schroeder's opinion, we are now running out of options for explicating the role of agent-relative value in deontology. However, many friends of consequentialization simply bite the bullet. ${ }^{13}$ They regard 'agent-relative value' as a theoretical term. The meaning of theoretical terms, such as 'electron', is determined by their function in a theory. The function of agent-relative value or of good-relative-to- $x$ consists in their contribution to a consequentialized deontological theory. We might therefore meaningfully speak of agent-relative value whenever this helps us to understand how the maximization of value can lead to deontological constraints.

However, if this is the aim it matters whether agent-relative value fits the explanatory structures of deontological theories. Consequentialized deontological theories should retain their original explanatory power when grafted on agent-relative value, and I will show that this is not the case for deontological theories which differ from consequentialism in their assumptions concerning moral accountability. Such theories are misrepresented when based on the maximization of agent-relative value. To clarify this claim, two ways of understanding the functional role of agent-relative value in consequentialized theories should be distinguished:

(a) functional contribution from the perspective of consequentialism,

(b) functional contribution as translation or grounding of deontological claims.

From a deontological point of view, agent-relative value should clearly satisfy (b). It should mirror the normative considerations that guide deontologists in postulating strict constraints. Yet friends of consequentialization are usually satisfied with (a). They consider the consequentialization of deontological theories as successful if everything is retained that matters to a consequentialist.

In fact, James Dreier claims that (a) contains all that should matter for a reasonable moral philosopher. His Extensionality Thesis (ExT) states that "nothing but extension matters in a moral view". ${ }^{14}$ The Extensionality Thesis builds upon the Extensional Equivalence Thesis according to which "each plausible moral view has a consequentialist extensional equivalent" (that is, plausible moral views can be consequentialized). If ExT is correct, (b) does not matter because (a) already establishes a consequentialist extensional equivalent to a deontological theory. Yet, how plausible is ExT? In ethics as well as in science, extensionally equivalent theories $\mathrm{T}^{*}$ need not have the same meaning or explanatory power as a theory $\mathrm{T}$. Ptolemaic astronomy lacked the explanatory power of heliocentric astronomy, although up to the seventeenth century it produced the same observable results concerning the position of stars. Similarly, an instrumentalist consequentialization of deontological theories might save all deontic phenomena (i.e., reproduce all duties, permissions, or commandments) but still be unsatisfactory because it fails to account for key deontological assumptions that lead to the respective phenomena (that is, justifies

13 E.g., Dreier (2011: 112).

14 Dreier (2011: 98). 
them). Mere extensional equivalence is simply not good enough with respect to established standards of theory comparison.

Dreier acknowledges as much in responding to an objection of Douglas Portmore. ${ }^{15}$ He therefore revises ExT by adding consequentialized counterparts of deontological justifications why we should heed deontological constraints (or other deontological demands). The resulting consequentialist theory $\mathrm{T}^{*}$ is not instrumentalist because it retains the explanatory power of T. For this to be the case, however, the consequentialized explanans should mirror the implications of the original explanans. This is impossible if explanatory structures of deontological ethics, which rely on specific assumptions concerning accountability, are replaced by assumptions concerning agent-relative value. The assumption of agent-relative value therefore misrepresents the normative reasons employed by such deontological theories, foreclosing a satisfactory consequentialization even if it saves the deontological phenomena, i.e., allows to derive the action-guiding deontic claims of deontological theories. Hence, a different way of consequentialization should be sought for such theories, one that relies on assumptions of accountability. As I am going to show, this project can dispense with agent-relative value altogether.

\section{Agent-relative accountability}

It has some significance that agent-relative value does not show up on a surface level in justifications of deontological constraints. Consider truthfulness or lying. Their value or disvalue appear neutral. Truthfulness is valuable regardless of whose truthfulness it is. My truthfulness is as valuable as yours in Kantian ethics. Moreover, all agents have reason to promote everybody else's truthfulness - just not at any cost, and especially not at the cost of their own lying. The respective difference seems to depend not on agent-relative value but rather on differentiated responsibility. Everybody is primarily responsible for their own truthfulness and only to a lesser degree for the truthfulness of others. This can be formulated more precisely with a distinction between attributability and accountability. ${ }^{16}$ Let the attributability of acts signify that an act can be attributed to a person as something for which she might in principle be held responsible according to some scheme of accountability. Accountability, by contrast, is always ascribed from the perspective of a specific scheme of moral accounting. Consciously failing to prevent others from lying would thus be attributable to a moral agent, because it has consequences for which a person might be morally responsible under some scheme of moral accounting (e.g., a consequentialist one). However, from a deontological point of view, the agent is not morally accountable for having failed to prevent the lying of others by lying herself. The agent is not even accountable for not attempting acts of prevention which would involve her own lying. Thus, in the specific deontological model of accountability suggested here, the

\footnotetext{
15 Dreier (2011: 112). Betzler and Schroth (2019: 122) require more for appropriate consequentialization but their skeptical outlook on its prospects of succeeding are connected to the centrality of agent-relative value or betterness for their approach.
}

16 See Eshleman (2014). 
respective omissions do not alter the agent's moral account. The suggested model of accountability ensures that the agent's potential responsibility for the lying of others cannot ground legitimate blame in a situation in which their lying could only have been prevented with a lie. Moreover, blaming the agent would be inappropriate not just because the agent's truthfulness is more valuable than preventing others from lying. In the present case, non-prevention is rather an action for which an agent is not accountable if prevention would have conflicted with a deontological constraint, such as the prohibition of lying.

Constraints are thus in many deontological ethics intricately connected with norms of accountability. Agents are primarily accountable for their own actions and to a lesser extent for preventing morally wrong actions of (fully responsible) other moral agents. Reference to fully responsible others is necessary here because moral agents can be accountable with respect to controlling (and educating) children or mentally disabled persons. Yet under normal conditions (and without institutional regulations or informational asymmetries as 'defeaters') a normally developed adult person is the paradigmatic example of an agent who is accountable for her own actions, whereas others are not accountable for the actions of an adult person. Let us call this view Separate Accountability:

Any mature person is accountable for her own actions and not for the actions of mature others.

I believe that Separate Accountability is implicit in classical deontological ethics from the Christian (scholastic) tradition to Kant. However, here is not the place to substantiate this historical claim. Let it suffice to assert that Separate Accountability can be used to justify strict deontological constraints and to clarify how deontological ethics might be consequentialized. It should first be shown that deontology can be put on this basis before further historical and systematic claims can profitably be addressed.

Separate Accountability allows that agents might be accountable for not discouraging others from moral wrongdoing. Agents are accountable in most deontological theories for not trying to prevent other persons' wrongdoing by warnings, good advice, denial of support, blaming or denunciation. However, this does not make them directly accountable for another person's wrongdoing. Even if an agent $X$ might be accountable and blameworthy for not having warned another competent adult moral agent $Y$ not to torture, $X$ is nevertheless not accountable for $Y$ 's acts of torture. As a morally competent adult, $Y$ needs to know better than to violate a strict deontological constraint, even if reminding him or her of this fact might have been obligatory. Moreover, the range of permissible interventions to discourage others from wrongdoing is limited by deontological considerations. The overall betterness of an outcome does not justify all means.

It follows that Separate Accountability might thwart the minimization of disvalue even if we regard the disvalue of a specific kind of constraint violation as agentneutral and equal in all cases. Let $d$ be a perfect duty. By violating $d, X$ would be accountable for producing disvalue $-v^{*}$. If $X$ omits morally licit, feasible actions that might prevent $Y$ from violating $d$ twice (producing disvalue $-2 v^{*}$ ), $X$ is accountable for this omission. Let us assume the act-value of licit actions aiming at 
the prevention of immorality (advising, discouraging etc.) to be $m$, regardless of the success of the actions. The act-disvalue of $X$ 's omission of such an action is thus $-m$. However, in typical cases of violating constraints to prevent a greater number of similar violations, $Y$ cannot effectively be prevented from twice violating $d$ by interventions that are morally licit from a deontological point of view. Otherwise, such interventions would be preferable to any prevention that involves a constraint violation. Hence, only violating $d$ can stop $Y$ from violating $d$ twice. Should $X$ therefore violate $d$ after having tried all deontologically licit other means in order to prevent $\mathrm{Y}$ from violating $d$ twice? From the perspective of moral account keeping embodied in Separate Accountability, clearly, not. A violation of $d$ would lower $X$ 's account by $m-v^{*}$ because a deontological value order will always assume $\mathrm{v}^{*}>\mathrm{m}$. (For simplicity's sake, I assume that moral agents should increase or at least not decrease the moral value they are accountable for). ${ }^{17}$ Yet what about the $-2 \mathrm{v}^{*}$ value loss that $X$ could have prevented by violating $d$ ? This loss does not register on $X$ 's account and is thus irrelevant for her moral accounting.

The picture emerging from this analysis is one of persons with separate moral accounts, each person being primarily concerned with her own balance sheet. Hence, we have a model with personalized moral accounts of act value, but it is important not to confuse these accounts with personal accounts for the merit or demerit of agents. On the so far discussed account, only universal act values are registered. The account aggregates the act values for which an agent is accountable. Issues of merit or demerit need to be handled separately (see below Section 4). However, separation of moral value creation from merit or demerit does not imply that persons should be disinterested in the value accounts of others. They may, as indicated, have a conditional duty to help others to prevent losses on their accounts. Nevertheless, this duty is limited. It does not infringe an agent's main responsibility to avoid losses on their own account.

To some observers it might appear inappropriately selfish to restrict one's primary responsibility to one's own moral account. ${ }^{18}$ After all, the present approach acknowledges that an agent could increase overall value by accepting responsibility more widely. This worry is thus a version of the already broached purity objection. Agent-relative accountability, as assumed here, seems to be inordinately preoccupied with the moral purity of the agent instead of focusing on the maximization of value. Moreover, we so far discussed a limited responsibility for the deeds of others but there is also the possibility of actively extending one's sphere of responsibility. Indeed, in some contexts there is nothing objectionable in extending one's responsibility (e.g., taking over responsibility from others). A person $X$ might be accountable for helping needy persons 1-5, whereas person $Y$ is accountable for supporting needy persons 6-10. Nevertheless, it would be good if $X$ also helped persons 6-10. Deontological ethics traditionally approve of such actions as meri-

\footnotetext{
17 Note that not all deontological ethics need to subscribe to value maximization. For some, doing good (i.e. actions with positive value balance) might suffice. Moreover, I assume that the agent with deontologically licit means first but in vain tries to prevent others from violating a constraint before she stops it through her own constraint violation. Hence, she is billed $m-v^{*}$ on her moral account.

18 I am grateful to a reviewer for this objection.
} 
torious or supererogatory, thus welcoming a certain type of voluntary extension of responsibility. Yet, there are other cases in which a voluntary extension of responsibility is not desirable from a deontological perspective. For deontologists, it is not meritorious to prevent two instances of torture by torturing once. Agents should not extend their responsibility in such cases. In fact, they are strictly prohibited from doing so. The question, of course, is how to draw a line between cases of permissible and impermissible extensions of responsibility.

One answer (but possibly not the only one) is that strict deontological prohibitions help us draw the line. Agents are not permitted to extend their responsibility beyond Separate Accountability at the cost of violating deontological prohibitions. Section 6 discusses an underlying reason for this restrictiveness: The deontological system of narrowly agent-relative accountability is optimal in a value maximizing sense. Hence, it is all things considered better not to allow agents to torture to prevent more torturing or rape to promote sexual inviolability. Note, however, that the high likelihood of miscalculation when trying to maximize the value of inviolability (or more specifically, of unviolated dignity) is from the present point of view not the key problem of such tradeoffs, although this is certainly also a major problem. For the present considerations, the crucial problem is rather that any permission to violate strict deontological prohibitions would undermine an optimal system of moral accountability. The system is optimal because it maximally represents and protects human freedom and dignity. Preventing false value maximization contributes to the system's optimality, but it does not exhaust it. It also matters that distributed accountability optimally mirrors deontological assumptions concerning moral responsibility. Separate Accountability is a core element of the separateness of persons which follows from their fundamental dignity, or so deontological ethics may assume. The suggested system of accountability thus has value because it intrinsically promotes human dignity, besides the extrinsic value of forestalling mistaken attempts at maximizing value. Under this premise, the purity objection can effectively be rebutted. Deontological agents are not primarily concerned with their own purity when upholding the deontological system of accountability but with implementing an optimal system of accountability (for detail see Section 6). ${ }^{19}$

It is also important that the outlined account model does not rely on agent-relative value. Of course, the accounts are agent-relative, because each agent has their own account. (We might also say that accountability is agent-relative). But the agentrelativity of accounting does not imply that the value of the currency on the account is agent-relative, too. Let us look at this claim a bit more in detail.

\footnotetext{
19 Quinn (1994: 173) also claims that the deontological moral outlook has intrinsic value: "The value that lies at the heart of my argument - the appropriateness of morality's recognizing us as independent beings - is in the first instance a virtue of the moral design itself.' I go beyond Quinn in associating this intrinsic value with structures of accountability.
} 


\section{The key account model}

We may compare deontological moral agents to key account managers in a firm. ${ }^{20}$ The revenue for which key account managers are primarily responsible is not theirs, that is, the value they manage is universal or neutral. It is the firm's money they manage, and each key account manager contributes to the good of the firm by diligently managing her account. Moreover, each key account manager is accountable only for their own account. The managers are primarily instructed to increase the value of their accounts. It is desirable that they help others to obtain good results, but not at any price. Meddling in foreign affairs is only acceptable if one's own account is well kept. Incurring serious losses at home to avoid higher losses of others is not acceptable behavior for key account managers - at least in the model of key accounting assumed here..$^{21}$

Of course, a key account model of moral accountability has its limitations. Key account managers are usually paid for doing their job. Hence, they are motivated by what is 'good for' them. In some deontological ethics, agents may also profit from diligent moral account management. The agent may be rewarded on earth or in afterlife for good moral accounting. However, this is an additional and in no way necessary assumption. From a Kantian point of view, you ought to do your duty even without expectation of reward. Moral key account managers may thus act out of duty and not for personal profit. There is nothing incoherent in such an assumption. In fact, some key account managers in non-profit organizations are unpaid and mainly motivated by unselfish motives. Hence, there is no necessary connection between key account managing and agent-relative value or egoistical motivation.

This is also relevant for dealing with a second personal moral account (I call it the private moral account), which may be conceived as an account of personal merit or demerit. Even agents who diligently manage their moral key account purely for duty's sake might have a private account of merit because doing one's duty may already be considered as meritorious. Moreover, many deontological theories acknowledge the possibility of supererogation, that is, exceeding one's duty for the sake of the common or universal good. This shows that a private account of merit and demerit may exist even for agents who are not motivated by selfish and thus agent-relative motives.

Together with merit and demerit, an agent's 'moral purity' might be registered on her private moral account. We have already discussed which problems undue concern with one's own moral purity engenders for deontological ethics. It is therefore important that the existence of an account on which purity is registered does not imply that agents are motivated by their moral purity. Acting for duty's sake or

\footnotetext{
20 Note than, in contrast to Separate Accountability, no close relation to traditional deontological theories is assumed for the key account model. The model embodies a value-based rendering of deontological accountability conceived for the purposes of consequentialization. Thus, it shows how modern deontology could proceed rather than making a claim about traditional deontological approaches. However, it might be worthwhile to investigate whether at least some forms of premodern Christian ethics assume valueaccountability relations akin to the key account model.

21 A considerable bandwidth in the rules and incentive structures of key accounting exists. I assume here an ideal-typical model that emphasizes distributed responsibilities.
} 
for a better world (motivations likely to resonate with deontologists) is not the same as caring for one's moral purity. Moreover, acting in accordance with a given system of moral accounting does also not presuppose undue concern with one's moral purity. Consequentialists and deontologists may simply comply with their respective systems of accountability because they consider them right or best.

It is therefore important not to conflate the moral accounts we have been talking about. One account is a moral key account, personally managed by the agent. This account registers the universal value of actions for which an agent is accountable. The second account is the agent's private moral account on which her merit or demerit is listed. It seems plausible to assume some connection between soundly managing one's moral key account and acquiring merit or demerit, but this connection need not be motivational in a way that is problematic for deontological ethics.

If the values for which agents diligently manage their moral key account need not be agent-relative (or egoistical), does it follow that they do not act for agentrelative reasons? This question brings us back to the McNaughton-Rawling-Hammerton definition of agent-relative normativity in Section 1. The reason to diligently manage my moral key account is agent-relative in their sense (as it is for most others approaches to agent-relativity in ethics). After all, I do not have a reason of the same strength to manage other agents' key accounts, and they do not have a strong reason to manage mine. Yet the agent-relativity of this kind of reasons is not peculiar to deontology. Consequentialists would also demand that each agent do their duty, that is, do what they are accountable for. Thus, in consequentialism the obligation to maximize value is also agent-relative. Each agent ought to comply with this obligation, and nobody has (a genuine and comparably strong) reason to take over the value maximization of others. In final consideration, consequentialist and deontological ethics therefore do not differ with respect to claiming that agents should do what they themselves are accountable for (implying agent-relativity). They rather operate with different systems of accountability.

Insofar, we may conclude that the assumption that agents should primarily manage their own moral account does not yet help us to distinguish consequentialism and deontology. What marks a significant difference is the agent-relativity of the accounting. In the present model of deontological accounting, each moral agent has her personal key account, which differs from all other key accounts. That is, the agents do not manage the same account or a shared account. We might also say that the system of accounts is agent-relative in deontological ethics. (At this point, it is again important not to conflate an individual's key account of universal value with her private account of merit.) Consequentialists, on the other hand, manage a shared account of universal value and are ceteris paribus called up to prevent others from creating losses for this account. In particular, to satisfy the act consequentialist demand that all moral agents should maximize universal value, agents may prevent others from creating losses. The existence of a single account of value managed by all agents is tantamount to the existence of an agent-neutral account, because the account does equally belong to all agents. Contrast this with the model of agentrelative moral key accounts in deontological ethics and you have a constitutive difference between consequentialist and deontological ethics. However, it does not amount to a difference with respect to the universality of the accounted value. The 
shared consequentialist account and the separate deontological key accounts register only universal values.

It might be objected that in business key accounting, the value (i.e. money) for which a manager is accountable belongs to a firm. It is thus agent-relative in comparison to other firms. However, to get rid of this objection, we just need to assume that moral key accounting is not done for the sake of subunits of a moral community but for whole moral communities. Or, from a realist meta-ethical position, moral accounting might simply deal with objective values. Under both premises, moral key accounting registers the universal good but not a particular good that might only be the good of some.

There is a second flaw in the analogy that deserves mention. In key accounting, it is implicitly assumed that this system of accounting is best for the profitability of a firm. Deontologists will similarly assume that their system of accounts is morally best. However, in business contexts it is theoretically possible for a key account manager to produce an overall better outcome for a firm (e.g., in terms of longterm profit) by neglecting her own account and helping others to manage their accounts. There is no analogy to this possibility in deontological moral accounting if helping others would require violations of deontological constraints. From the present deontological point of view, no violation of deontological accounting rules might prove overall better (i.e., lead to a morally better world) than compliance (see Section 6). This is a crucial assumption that buttresses strict deontological constraints.

Finally, we should discuss whether contrary to deontological constraints, the key account model calls for single person tradeoffs of inviolability or dignity between time periods.

\section{Can there be a 'paradox of deontology' for personal moral accounting?}

What if an agent could bar herself from multiple acts of torturing only by torturing

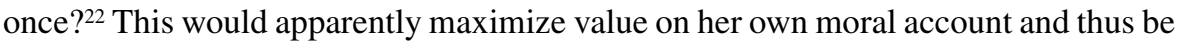
demanded by the key account model. Any justification of torturing would, however, violate a strict deontological prohibition of torture. It is therefore important to dispel the appearance of a conflict between the key account approach and the demands of deontological ethics.

The key to a solution to this alleged problem is implicit in the assumption of Separate Accountability. In the multi-person case, person $X$ is accountable for her acts of torture while others are accountable for their acts of torturing. In the single person, multi period case, Separate Accountability assumes only one locus of accountability (namely $X$ ) but note $X$ 's set of options for maximizing value on her own moral account. $X$ can refrain from torturing now and in any future time-period.

\footnotetext{
22 Betzler and Schroth (2019: pp. 130) regard the single person, multi period case as a potent problem for deontology even after consequentialization. As argued here, it is not a problem once the specific assumptions of deontological accountability receive due attention.
} 
This is obviously the best option from a deontological perspective in the singleperson case and one that does not require any trade-off between present and future acts of torturing. Hence, a deontologist should not accept the assumption that $X$ 's future renunciation of torture is only achievable by torturing now, except it is precisely explained how this can come about. Persons who are morally accountable in the ways assumed by Separate Accountability can, in principle, at all times refrain from torturing. This follows from the assumption of free moral agency which underlies deontological assumptions of accountability. Morally accountable persons are therefore able to maximize value on their own moral accounts by not torturing at all.

Critics might try to overturn this result by adding assumptions to discussed cases. It might be stipulated, for instance, that a person $X$ will at a future time $t^{*}$ become psychotic, or be drugged, or under control of a mad scientist. Under all these conditions it is assumed that $X$ will torture many people at $t^{*}$. This can, so goes the story, for some reason only be prevented by torturing somebody now. However, the listed conditions imply that $X$ is at $t^{*}$ not a morally accountable agent but either of unsound mind or a mere instrument of others. Thus, the issue is not one of balancing a personal moral account over two or more periods of time, e.g., by avoiding future negative entries at the cost of a smaller negative entry now. $X$ acts accountably only now, and negative entries at $t^{*}$ on $X$ 's account can therefore not exist. In the madscientist scenario, the answer is analogous to the multi-person case. The mad scientist is accountable for future acts of torture, $X$ is only accountable for torturing or refraining from torture now.

In the lunacy scenario, $X$ could apparently prevent future acts of torturing committed by a not morally accountable agent $Y$ only by torturing a human being now. ${ }^{23}$ However, for $X=Y$ this assumption is illicit because $X$ always has the additional option of killing herself before (full) lunacy sets in. This leads to the question whether warranted epistemic certainty of becoming a psychotic mass killer or torturer engenders a duty, or at least a permission, to stop oneself even at the cost of killing oneself before it is too late. The question of such a duty or permission, and whether deontological ethics should postulate it, is not co-extensive with the question whether the key account model is sound. In any case, under the premise of a duty to prevent oneself from becoming a monster, clearly no accounting problem exists. $X$ would maximize value on her moral key account by killing herself before morphing into a torturing monster. Given the assumed duty, this would be better in terms of moral key accounting than preventing torture by torture.

Of course, for religious deontology it is a thorny general question whether human beings are morally obligated to sacrifice their lives if they thus and only thus can avert disasters with many casualties. If this is denied in cases of natural disasters or in wars, the same should hold in the lunacy scenario which is akin to a natural disaster once we assume that $X$ becomes psychotic without fault of her own (or if $X=/=Y$ ). From many deontological points of view (similar cases are discussed in medieval Christian ethics), an agent who refuses to sacrifice her life is not held ac-

${ }^{23}$ We might assume, for instance, that at the present stage of $X$ 's psychosis an act of torture has so shocking psychological consequences for $X$ that it would stop the progression of the psychosis. 
countable for a subsequent disaster which she did not bring about as an accountable agent but could only have prevented at the cost of her life. This leads to a second way to avoid the balancing of one's present and future acts of torturing. Under the outlined assumption, the future disaster will not appear on the individual's moral balance sheet, whereas killing herself would. Hence, $X$ should not kill herself. Some moral philosophers, and most likely all consequentialists, will find this solution unpalatable. Yet, this is presently not our concern. The relevant point is that deontological ethics can solve (and have solved) hard cases in the outlined way, which is compatible with Separate Accountability. There is thus no discrepancy between the demands of deontology and Separate Accountability or for that matter, the key account model.

Another assumption that alters the basic case of ' $X$ tortures now to prevent multiple subsequent acts of torture by herself' is that $X$ at present or at $t^{*}$ acts under duress. However, this assumption soon devolves into the already broached question whether $X$ is obligated to accept death or being tortured herself in order to prevent her own multiple acts of torturing in the future. A new aspect is that duress might alter the conditions of accountability for $X$. The case is thus again not one of a straightforward balance of present and future evils of torture. It also matters whether entries are made (and possibly their size) on P's moral key account, but due to these changes no principled threat to the key account model as such emerges.

To sum up, it can be concluded that multi-period, single agent cases of value tradeoffs of the kind associated with the alleged 'paradox of deontology' pose no insuperable obstacles to the key account model or the assumption of Separate Accountability. This is true at least under a deontological perspective. Consequentialists will not like the suggested solutions. However, this is only to be expected given that both schools of ethical thought stand in steadfast opposition to each other.

\section{Consequentialization, agent-relative value, and agent-relative accountability}

Agent-relative value is often considered as central for the consequentialization of deontological theories. ${ }^{24}$ As indicated, consequentialization amounts to a reconstruction of deontological ethics as a value maximizing variant of act consequentialism. Consequentializers usually claim that all important tenets of deontology, and especially all deontic demands (duties, rights, prerogatives, etc.), can be salvaged in this process. Of course, the viability of the process is controversial, but it would still be good to know whether consequentialization could also proceed on the basis of agent-relative accountability, shunning agent-relative value in the process.

This is what I want to show in the present section. Deontological assumptions concerning accountability can be salvaged in consequentialization without any need to rely on agent-relative value. Moreover, the principle of Separate Accountability ('Any mature person is accountable for her own actions and not for the actions of mature others') can be combined with the maximization of outcome value within a set

24 Dreier (2011), Louise (2004), Portmore (2011: 62). 
of actions for which an agent is accountable. Of course, maximization of outcome value within a set of actions for which an agent is accountable is also demanded by consequentialism. According to standard act consequentialism, everybody is uniformly accountable for everything he or she can bring about and be it the prevention of other persons' violations of deontological constraints. Consequentialist accountability thus comprises the whole feasible set $A$ of an agent's actions. Whatever is attributable to an agent (i.e., what the agent might be held responsible for) is subject to her obligation to maximize value. In contrast, Separate Accountability leads to a restriction of $A$. Thus, accountability is narrower in the suggested understanding of deontology than in consequentialism. In the consequentialization of deontological theories we may therefore assume that moral agents maximize value in a reduced choice set $R C$ which only contains actions for which they are accountable from a deontological perspective. ${ }^{25}$

The value to be maximized (or disvalue to be minimized) in $\mathrm{RC}$ is agent-neutral. Take, for instance, the disvalue of torturing a human being. An agent, who refuses to torture although she thereby would prevent two instances of equally horrible torture, fails to minimize overall agent-neutral disvalue. The agent may, indeed, agree that two acts of torture are agent-neutrally worse than a single act of the same kind of torture. However, the agent minimizes the agent-neutral disvalue accountable to her. Acts of torture done by others are to be registered on their moral accounts and do not undercut our agent's account-relative value maximization.

It is conceivable that consequentializers (and consequentialists) will not be satisfied with this solution since it fails to derive all deontic demands from a betterness ranking of states of affairs. As presently modeled, deontological constraints are justified by assumptions concerning accountability and value (or disvalue) but not derived from considerations of value (aka goodness or betterness) alone. Consequentialization should therefore include a further step that justifies deontological accountability by representing it as result of value maximization. In fact, it is not difficult to add such a further step. $R C$ and Separate Accountability are both grounded in the values of freedom, autonomy, or dignity of human beings. Of course, not all deontologists may want to start from there. Kantians may insist that accountability is not determined by considerations of value but by reason. Thus put, accountability follows from the meaning of the concepts of freedom, autonomy, or dignity and not from any value they might have. For many Kantians, therefore, consequentialization cannot succeed because their assumptions concerning accountability cannot be derived from a value ranking. Nevertheless, other deontologists and even other kinds of Kantians may accept that Separate Accountability follows from the values of freedom, autonomy, and dignity, which for ease of reference are called 'values of personality' here. What is far from clear, however, are the details of the assumed process of derivation. It therefore helps to keep the structure of the present argument in mind. We are giving consequentialization the benefits of doubt, that is, we ask

\footnotetext{
25 For act consequentialization, I assume here a value maximizing form of consequentialized deontology. For some forms of deontology, a satisficing consequentialist model might be more appropriate. For the rest, I presently do not want to take a stance in the debate on the rationalizability of mere satisficing (see Byron 2004), because nothing of relevance hinges on this debate for the present paper.
} 
for the implications of consequentialization assuming it would be feasible. Let us therefore assume that Separate Accountability is the model of accountability that represents maximal concern for the 'values of personality' from a deontological point of view (some defense of this assumption follows below). Would it then be appropriate to announce: Consequentialization accomplished?

In fact, the announcement would be premature. There is still a lingering problem with the resulting theory structure. The outlined process of consequentialization leads to a two-step consequentialist procedure. In the first step, maximization of the agent-neutral 'values of personality' produces a structure of accountability which reduces $A$ to $R C$. In a second step of maximization, agent-neutral value is maximized in $R C$, i.e., on the agent's moral account. The two steps of maximization are strictly separate and sequential. The second step builds on the results of the first. The emerging picture is, of course, familiar to consequentialists. It resembles the modus operandi of strict rule consequentialism, a two-step procedure which selects the best rule for action and then strictly demands compliance with the selected rule. Many consequentialists and non-consequentialists alike regard strict rule consequentialism as a spuriously consequentialist doctrine. It is called consequentialist and displays some elements of consequentialism, but, on reflection, it is no more consequentialist than a strawberry is a real berry according to botanical classification. Indeed, if maximization of value (in effect or expected) is characteristic of consequentialism, strict rule consequentialism fails because it eschews value maximization in cases where non-compliance with an otherwise optimal rule would produce more value than compliance (all things considered and even in the long run). ${ }^{26}$ From this perspective, the only truly consequentialist rule consequentialism is one of rules of thumb but not of strictly binding rules.

However, the two-step procedure suggested here differs in a crucial respect from strict rule consequentialism. Under the assumed deontological premises, no act of non-compliance with deontological accountability can all things considered be better than compliance. Compliance with deontological accountability engenders the deontologically best feasible world. Thus, the two-step procedure always produces the best consequentialized outcome. Nothing in the process of consequentialization compels us to abandon this claim. It just needs to be translated into appropriate ranking assumptions for values. One possibility is to assume that the values of personality (i.e. a compound of freedom, autonomy, dignity) are lexically prior to other values. Since the other values are then irrelevant for the maximization of the values of personality, the latters' maximization may precede that of other values. However, this does not yet fully accomplish the job.

It needs to be considered whether maximizing the values of personality might justify accountable violations of personality. That is, it needs to be explained why, under deontological premises, such offsetting cannot occur within the range of lexically prior values. (So far, I have only argued for the lexical priority of values of

26 The familiar alternative to this possibility is letting rule consequentualism collapse into act consequentialism by allowing for rules that explicitly prescribe what is right in each possible case of action, regardless how specific the case description needs to be (see Lyons 1965). I assume here that rule consequentialism is not reduced in this way to a mere façon de parler. 
personality). In fact, two times a lexically prior value $v^{*}$ would be more than one times $v^{*}$. Lexical priority allows for this kind of arithmetic. Yet, crucially, the system of deontological accountability embodies the values of personality from a deontological point of view. In fact, on the present account of deontology, the system of deontological accountability promotes the values of personality so much that this effect cannot be outweighed by losses of value incurred by upholding the system of accountability. In choices between worlds in which the system of deontological accountability is implemented and worlds in which it is not implemented, the former are always better from a deontological point of view (as presently conceived), and they always promote the values of personality to a higher degree. In consequence, in all possible worlds in which the 'values of personality' are maximized and deontological accountability is an option (as in our world), maximization will demand deontological accountability.

However, is it not outrageous to assume that a defense of the deontological system of accountability, which is supposed to embody the values of personality, would justify the non-prevention of arbitrary losses of individual freedoms, dignity, or autonomy? Imagine an evil emperor threatening to torture all humans unless a consequentialist system of moral accountability is universally accepted. Consequentialists, of course, will prefer to comply with the evil emperor. What matters presently, however, is only the reaction of deontologists, and specifically hard-nosed deontologists. For them, it is constitutive of our personality that all of us are accountable for their actions and not for the actions of others. This is a basic concomitant of what is often called the 'separateness of persons'. In possible worlds, in which this separateness is violated, our personality is denied, and hard deontologists assume that these are worlds not worth defending or living in. Hard choices might force us to choose between such a world and death, but preferring death to being unfree or becoming a torturer is recommendable from a deontological perspective. Note that I am not discussing the reasonableness of such a stance here. Our present concern is solely to comprehend or rationally reconstruct the internal logic of strict deontological reasoning, and my claim is that the offered considerations fit this logic much better than any assumption of agent-relative value.

In any case, our exercise of consequentializing deontological accountability documents that deontologists need to embrace two separate claims and not merely the claim that values of personality have lexical priority. Deontologists should also assume that deontological accountability has its own, supreme value. Under this premise, it cannot be optimal to minimize constraint violations since this process would lead to a violation of deontological accountability. This second claim is a crucial insight which otherwise might easily get lost. Attempts at consequentialization thus prove helpful for deontologists.

Under the outlined premises, a two-step approach of value maximization is compatible with the act-consequentialization of the underlying deontological theory. The resulting rule consequentialist surface structure is, on reflection, unproblematic. The reason is that act maximization will in each single case lead to the imposition of deontological accountability. Subsequent maximization in accordance with deontological accountability can be regarded as a posterior step of a single instance of value 
maximization, because the maximization of a set of values that includes insuperably superior values may proceed by level of priority.

Such maximization is therefore also compatible with the Compelling Idea. The Compelling Idea, which accounts for much of consequentialization's attractivity, states that the best action must always be permissible. ${ }^{27}$ This claim is usually assumed to refer to the best action in a feasible set $A$ of an agent's actions. Prima facie, a prohibition of torture even though an act of torture would overall minimize torturing will ceteris paribus not permit the best action in $A$ to be performed because prima facie less torture is better than more torture. Yet, such considerations of balancing miss crucial implications of the presently assumed maximization process. Under the assumed deontological premises, an appropriately comprehensive valuation of personality needs to heed the value of separate moral accountability. Hence, all things considered, a refusal to torture is better than preventing multiple acts of torturing if the value of an appropriate system of accountability is weighed in. In the end, thus, the Compelling Idea is vindicated, and its intuitive attractiveness is harvested for deontological ethics.

All this is possible without invoking agent-relative value. Agent-relative value has no role in the outlined maximizing considerations. In the first step, accountability is agent-neutrally determined by the universal 'values of personality' (freedom, autonomy, dignity). That is, accountability is determined by choosing the system of accountability that optimally promotes human freedom, autonomy, and dignity for all agents. In a second step, agents are called up to maximize the agent-neutral value they are morally accountable for. Again, it is not necessary to assume agentrelative value. Attempts to saddle deontological ethics with a deep-sitting necessary relationship to agent-relative value therefore misrepresent the normative structure of deontological theories and lead us astray.

\section{Conclusion}

The present argument has confirmed agent-relativity as distinguishing mark of deontological ethics. The reasons for complying with deontological constraints are agent-relative since deontological moral accounting is agent-relative. In fact, different core assumptions concerning the moral accounting of agents seem well-suited to distinguish deontology and consequentialism. Consequentialists assume that all agents maximize a common, agent-neutral account of universal value. Deontologists, by contrast, postulate separate agent-relative personal accounts for which universal value is maximized. Consequentialist and deontological theories are therefore distinguishable in virtue of the agent-neutrality and agent-relativity of their accounting practices. This may well be the most fundamental difference between consequentialism and deontology.

A structural difference in the accounting practices between these ethical schools persists even if the presently assumed form of deontology is consequentialized, that is, for the rest transmuted into a form of universal value maximizing act conse-

27 Not everybody finds the Compelling Idea compelling. For a critique, see Hurley (2017). 
quentialism. Differences in accounting are not reflecting the presence or absence of value maximization but different assumptions concerning the optimality of accounting models, including their contribution to a morally best world. Thus, there can be differences between deontology and consequentialism despite successful consequentialization.

As shown, it is not necessary to assume agent-relevant value at a fundamental level in deontological ethics. This is not to say that agent-relative value can have no role in deontological ethics, but only that it is not required and especially not for grounding deontological constraints. Many deontological theories, for instance, include agentrelative prerogatives (i.e. for pursuing valuable projects or for prioritizing one's own kin). In light of the present approach, it should, of course, be asked whether such prerogatives really rely on agent-relative value or whether they, too, arise from assumptions of accountability. Yet even if agent-relative value is introduced in deontological ethics via prerogatives, the respective value is value for persons. Prerogatives of the mentioned sort are good for the persons who have them or for the persons whom they benefit. ${ }^{28}$ In a similar way, agent-relative 'value for' can be introduced in consequentialist ethics, for instance, by giving weight to egoistical maximization. Yet, and this is a significant implication of the present argument, 'value for' might well be the only kind of agent-relative value that consequentialist or deontological ethics can legitimately employ. There is no other sort of agentrelative value at hand which they might want to incorporate. This goes some way to mitigate Mark Schroeder's qualms with the elusiveness of the concept of agentrelative value. Agent-relative value that is not 'value for' or relative to an agent's perspective may, in fact, be a mirage.

Funding Open Access funding enabled and organized by Projekt DEAL.

Open Access This article is licensed under a Creative Commons Attribution 4.0 International License, which permits use, sharing, adaptation, distribution and reproduction in any medium or format, as long as you give appropriate credit to the original author(s) and the source, provide a link to the Creative Commons licence, and indicate if changes were made. The images or other third party material in this article are included in the article's Creative Commons licence, unless indicated otherwise in a credit line to the material. If material is not included in the article's Creative Commons licence and your intended use is not permitted by statutory regulation or exceeds the permitted use, you will need to obtain permission directly from the copyright holder. To view a copy of this licence, visit http://creativecommons.org/licenses/by/4. $0 \%$.

\section{References}

Alexander, L. and M. Moore. 2016. Deontological Ethics. Stanford Encyclopedia of Philosophy. Ed. E. N. Zalta. The Metaphysical Research Lab. http://plato.stanford.edu.

Betzler, M. and J. Schroth. 2019. The Good of Consequentialized Deontology. In: C. Seidel (ed.), Consequentialism: New Directions, New Problems. Oxford: Oxford University Press, 115-135.

Brown, C. 2011. Consequentialize This. Ethics 121: 749-771.

Bykvist, K. 2018. Agent-Relative and Agent-Neutral Reasons. In: D. Star (ed.), The Oxford Handbook of Reasons and Normativity. Oxford: Oxford University Press, 821-839.

28 It might be asked whether prerogatives can have agent-neutral value but there is no space here to discuss this question. In any case, the prerogatives usually discussed with respect to deontological ethics are agentrelative. 
Byron, M. (ed.). 2004. Satisficing and Maximizing: Moral Theorists on Practical Reason. Cambridge: Cambridge University Press.

Dougherty, T. 2013. Agent-Neutral Deontology. Philosophical Studies 163: 527-537.

Dreier, J. 2011. In Defense of Consequentializing. In: M. Timmons (ed.), Oxford Studies in Normative Ethics 1. Oxford: Oxford University Press, 97-118.

Eshleman, A. 2014. Moral Responsibility. Stanford Encyclopedia of Philosophy. Ed. E. N. Zalta. The Metaphysical Research Lab. http://plato.stanford.edu.

Foreman, E. 2014. An Agent-Centred Account of Rightness. Ethical Theory and Moral Practice 17: 941954.

Gaus, G. 2001. What is Deontology? Part I and II. Journal of Value Inquiry 35: 27-42, 179-193.

Hammerton, M. 2017. Is Agent-Neutral Deontology Possible? Journal of Ethics and Social Philosophy 12: 319-324.

Hammerton, M. 2019. Distinguishing Agent-Relativity from Agent-Neutrality. Australasian Journal of Philosophy 97: 239-250.

Hurley, P. 2013. Consequentializing and Deontologizing: Clogging the Consequentialist Vacuum. In: M. Timmons. (ed.). Oxford Studies in Normative Ethics 3. Oxford: Oxford University Press, 123153.

Hurley, P. 2017. Why Consequentialism's ‘Compelling Idea' Is Not. Social Theory and Practice 43: 2954.

Korsgaard, C. 1993. The Reasons We Can Share: An Attack on the Distinction Between Agent-Relative and Agent-Neutral Values. Social Philosophy and Policy 10: 24-51.

Louise, J. 2004. Relativity of Value and the Consequentialist Umbrella. Philosophical Quarterly 54: 518536.

Lyons, D. 1965. The Forms and Limits of Utilitarianism. Oxford: Oxford University Press.

McNaughton, D. and P. Rawling. 1991. Agent-Relativity and the Doing-Happening Distinction. Philosophical Studies 63: 167-185.

McNaughton, D. and P. Rawling. 1995. Agent-Relativity and Terminological Inexactitudes. Utilitas 7: 319325.

McNaughton, D. and P. Rawling. 2007. Deontology. In: R. Ashcroft et al. (eds.), Principles of Health Care Ethics. New York: Wiley, 65-71.

Nagel, T. 2002. Personal Rights and Public Space. In: T. Nagel (ed.), Concealment and Exposure. Oxford: Oxford University Press, 31-52

Portmore, D. 2011. Commonsense Consequentialism: Wherein Morality Meets Rationality. Oxford: Oxford University Press.

Quinn, W. 1994. Morality and Action. Cambridge: Cambridge University Press.

Ridge, M. 2017. Reasons for Action: Agent-Neutral vs. Agent-Relative. Stanford Encyclopedia of Philosophy. Ed. E. N. Zalta. The Metaphysical Research Lab. http://plato.stanford.edu.

Schroeder, A. 2017. Consequentializing and Its Consequences. Philosophical Studies 174: 1475-1497.

Schroeder, M. 2007. Teleology, Agent-Relative Value, and 'Good'. Ethics 117: 265-295. 